\title{
COURT INTERPRETER TRAINING IN THE LANGUAGE LABORATORY
}

\author{
Wayne H. Stromberg \\ Gerald L. Head
}

\begin{abstract}
Demographic studies and statistics from state and federal courts indicate a growing need for Spanish-English court interpreters with special training in consecutive and simultaneous court interpretation. The authors conducted a survey of 466 of California's Spanish-English court interpreters to determine what the Spanish-English court interpreter's strongest skills needs are. Survey results are reported in this article, and the five strongest skills training needs are identified. The authors indicate how the language laboratory may efficiently be used to develop and enhance these five skills and how it may best serve a court interpreter training program. Emphasis is on applying the work of G.A. Miller and the training techniques of Robert Ingram to Spanish-English court interpreter training.

KEY WORDS: Court interpreting, court interpretation, court interpreters, simultaneous interpreting, simultaneous interpretation, simultaneous interpreters, consecutive interpreting, consecutive interpretation, consecutive interpreters, interpreter training, language laboratories, learning laboratories.
\end{abstract}

The United States is in the midst of a rapid demographic change. Between 1970 and 1980, the nation's Hispanic population increased by more than $42 \%$, and reached a 1980 total of about $14,609,000$ people, or $6.4 \%$ of the nation's population (1). Of this number, 1980 Census Bureau estimates indicate that 11,017,606 Hispanics speak only Spanish at home; $2,763,686$ (about $19 \%$ ) claim very little or no English (2). With some political and economic realities in Latin America worsening during the 1980 's, it is highly probable that the influx of Hispanics, some with minimal English skills, will increase significantly. (Presently, net immigration of Hispanics is estimated to be $1,000,000$ per year.) The nation's Hispanic population may well become the nation's largest minority group in less than 40 years, with an estimated 47 million members.

Insuring the legal rights of this large population in courtroom proceedings, under the sixth amendment to the Constitution, (3)

Wayne H. Stromberg is the Director of San Diego State University's Foreign Language Laboratory in San Diego, California. He received his Ph.D. in philosophy from the University of California at San Diego in 1975 and has held his present administrative position since 1980.

Gerald L. Head is the Director of the Certificate Program in Translation and Court Interpreting offered through the Department of Spanish and Portuguese at San Diego State University. He received his doctorate in Hispanic languages and literatures from UCLA in 1964 and has been a member of the SDSU faculty since that year. 
requires that they be provided with professional, highly skilled court interpreters. These interpreters are required by law to pass the most rigorous and demanding exams before they may work in federal courts; state laws often require that they meet state certification requirements as well before they may be employed in superior and municipal courts (4).

Clearly there is a need for strong court interpreter training programs in the nation's universities, community colleges, and private institutions. A few such programs are now emerging and many more are needed. The language laboratory has an indispensible role to play in these developments.

The objectives of this paper are twofold. An effort will first be made to establish skill requirements and training goals for the aspiring or beginning court interpreter (henceforth $\mathrm{CI}$ ). A variety of training techniques which address these skills, and are suitable for the language lab, will then be described. A brief summary of the goals to be met in a $\mathrm{Cl}$ training program in the lab will conclude the paper.

\section{Skill Requirements and Training Needs for the Court Interpreter}

There are five kinds of interpreting that may be required of the court interpreter. 1) Consecutive interpretation is submitted when the interpreter allows the speaker to complete one or more sentences before beginning to interpret. 2) simultaneous interpreting, the interpreter begins to speak within a few seconds of the person whose speech is being interpreted and interprets during the speaker's remarks. Simultaneous interpretation is almost always from English to Spanish, and often has the function of making the proceedings intelligible to a defendant who is not participating in the dialogue being interpreted. 3) Summary interpreting requires of the interpreter that he summarize a document, tape, conversation, etc., rather than give a word-for-word interpretation. It is rather rare, and is used when brevity is required and the judicial process will not be jeopardized. 4) Tape transcription (very rarely done) requires of the interpreter that he transcribe literally and accurately the recorded contents of a tape. 5) Sight translations (also very rare) will be submitted when the court asks an interpreter to translate written material without summarizing.

The authors conducted a needs assessment survey of Spanish-English court interpreters to determine the skills most needed to perform the more common of these interpretive tasks. The survey requested a ranking of twenty-two interpreter skills according to their difficulty and their importance, and using the four-point scale reproduced in Table 1 (Appendix). The survey was administered by mail in July 1982 to 466 members of the California Court Interpreters' Association. The return rate by deadline was $26 \%$. Results were 
tabulated by computer. Respondents' ratings of interpreter skills and abilities are encapsulated in Tables 2 and 3 (Appendix). Table 2 indicates the mean values assigned by survey respondents for difficulty of each interpretational skill or ability; Table 3 contains the mean values assigned for the importance of each skill. The skills are listed in order from least difficult or important to most difficult or important. Four skills were judged by survey respondents, very important to the beginning interpreter and difficult as well. These are:

1. Maintaining concentration during interpretation

2. Remembering the content of statements while engaged in consecutive interpretation

3. Ability to "keep-up" accurately with the witness during simultaneous interpretation

4. Knowledge of English legal terms

A fifth skill, considered the most difficult of all those skills listed for the beginning interpreter, was thought by respondents to be only slightly less than these four in importance:

5. Ability to manage very long sentences when doing consecutive interpretation

Survey results make it clear that these five skills or abilities should be given the highest priority in $\mathrm{Cl}$ training programs (5).

\section{The Language Laboratory in Court Interpreter Training}

The function of the language laboratory in the $\mathrm{Cl}$ training program is entirely that of instructional support and service. While some types of training aids can be composed by the staff of some labs (those fortunate enough to have the requisite language skills and teaching experience), it will rarely be the case that the staff of a foreign language laboratory will be capable of initiating a viable $\mathrm{Cl}$ training effort without guidance from skilled foreign language faculty in an established academic program. The following remarks accordingly describe the most valuable service and support functions which labs may provide for an existing or contemplated $\mathrm{Cl}$ training program, under the oversight of a court interpreter trainer.

Developing the five skills which the beginning interpreter needs most, and finds most difficult, requires especially designed and produced language laboratory training tapes. The lab staff and the $\mathrm{Cl}$ trainer must consider: (1) a source of material for tapescripts and audio tapes; (2) design of tape exercises to teach instructional goals (i.e., the five skills); and (3) equipment needs.

The first step is to locate a good source of realistic material which may be taped. One promising alternative is to contact local 
courts, and especially municipal and immigration courts, to inquire about the possibility of making recordings while courts are in session. It may be possible, as well, to obtain transcripts of court proceedings at low cost or at no expense, and attorneys may allow access to transcripts of depositions. And, of course, scripts may be written by the trainers themselves. Whatever source of materials may be chosen, it is essential that they be realistic (6).

Typescripts may then be prepared of the collected materials, and sentences and passages may be selected, edited, and organized by trainers. Scripts may then be made of these and the scripts audiotaped. When the trainee uses the tape in the language laboratory, he should do so with his instructor monitoring and correcting him. In additional drills and practice he may work on his own.

\section{Maintaining concentration during interpretation}

Certainly one of the most important skills attributed to the court interpreter is his ability to concentrate for long periods of time on his interpretive duties, whether they involve simultaneous or consecutive interpretation. Such concentration skills are usually taught with any of a variety of traditional "decalage" techniques. These techniques involve "shadowing" exercises (for instance, the student will repeat the words on the tape, or will translate them, while maintaining a steady lag behind the tape of either one, two, or three words), These exercises may be used in combination with memory or concentration exercises requiring the performance of a simple, repetitive mathematical operation. For instance, a word list in Spanish might be recorded on audio tape. A trainee might then be asked to listen to and try to remember the words, while simultaneously writing on a piece of paper the series of even numbers from 100 to 0 . When he is able to do this fairly easily, he might then be asked to do the somewhat more difficult task of remembering the content of a dialogue while jotting down every third number from $100(100,97$, $94,91 \ldots)$.

These techniques, and similar ones, do seem to assist in developing concentration skills, but are not an ideal vehicle for doing so. Shadowing and translating a word list does not bear much resemblance to shadowing and interpreting a sentence or a clause. And the trainee working on such methods as these is often required to concentrate, not on reasonable typical interpretive chores, but on a combination of linguistic and mathematical tasks.

These difficulties can be overcome by making use of a decalage technique recently described by $\mathrm{Mr}$. Robert Ingram, a sign language interpreter trainer (7). Mr. Ingram's decalage techniques are designed to teach skills needed by sign interpreters and foreign language interpreters alike, and adapt well to Spanish-English $\mathrm{Cl}$ programs. Of special interest to the $\mathrm{Cl}$ trainer is Ingram's use of "cue words" and of 
the well-known research of G.A. Miller on storage of information in sensory input processing.

Miller argued, in 1956, that individuals can retain only a small number of "chunks" of information (seven is common) in immediate memory. However, the amount of information included in each of these chunks is amenable to increase by learning--by improving the organization or packaging of information in each chunk. Thus, one of the objectives of the $\mathrm{Cl}$ trainer should be to encourage the trainee to "chunk" more and more information, by learning to include more and more "bits" of information in each chunk.

"A man just beginning to learn radiotelegraphic code hears each dit and dah as a separate chunk. Soon he is able to organize these sounds into letters and then he can deal with the letters as chunks. Then the letters organize themselves as words, which are still larger chunks, and he begins to hear whole phrases...I am simply pointing to the obvious fact that the dits and dahs are organized by learning into patterns and that as these larger chunks emerge the amount of message that the operator can remember increases correspondingly. In the terms I am proposing to use, the operator learns to increase the bits per chunk." (8)

Miller's work can be applied to interpreter training via Ingram's decalage technique. This technique requires that the instructor write scripts of a certain description. In each sentence in the script a certain word, selected by the trainer as a cue word, will appear. In the following sentences, for instance, the word "left" may serve as a cue to the trainee; he is instructed to begin shadowing the sentences when he hears this word in the sentence, and not before. (The examples are not Ingram's.)

1. He left early that day.

2. His friend John left late yesterday.

3. He and the children had not left by dinnertime last night.

4. How long did Mr. Ramirez say it would be before he left for home with his family?

5. Do you really think that he intended to call on his sister before he left the Bakersfield area to return to school at Berkeley?

Each succeeding sentence is longer, and the common cue word is positioned later in each succeeding sentence. It is always followed by additional material. The student or trainee will be required to shadow the tape when he hears the cue word (without translation at first), and in order for him to do so, he must do two tasks at once.

First, he must organize (chunk) and remember the information that appears in the sentence before the cue word appears, and after it appears. To cite Ingram,

"What we want students to learn in this exercise is how to chunk information; i.e., we want them to learn how to organize incoming messages in blocks of information rather than as separate words." (9) 
The student will be processing information units, or bits, and learning how to process them rather than translating a list of words.

Second, the student must simultaneously concentrate on recognition of a lexical item--the cue word--and on beginning the shadowing process when he recognizes it.

When the student becomes quite proficient at these exercises, he will add the ingredient of interpretation from the source language--either Spanish or English--to the target language, with the interpretation beginning on the appearance of the cue word. Throughout this practice and drill, the student's efforts are directed at interpretive chores and skills, rather than a combination of linguistic and mathematical tasks.

While Ingram's decalage technique, using such scripts, was not advanced as a mechanism for developing concentration, it seems an excellent vehicle for doing so for it requires that the student master concentration skills while developing immediate-memory capacities.

\section{Ability to "keep up" accurately with the witness during simultaneous interpretation.}

In simultaneous court interpretation, the interpretation will almost always be from English to Spanish, and a good form of shadowing exercise is needed to develop the trainee's skills. The student must be presented with English-Spanish exercises of varying degrees of complexity and speed, and required to interpret them simultaneously with minimal errors. Moreover, as before, the trainee must be encouraged by the taped exercises to interpret and recall, not individual words, but larger units of information; he must recall word groups.

His guides in breaking the source text up into chunks of speech or information will include grammatical junctures (subject-object clauses, prepositional phrases, etc.). Often, pauses will be the indicators of such junctures. As Barik notes,

"Performance may be thought to depend on the extent to which or frequency with which pauses in the (speaker's) delivery occur at grammatical junctures. A pause at such a juncture characteristically bounds a "meaningful" segment of speech, on which the interpreter can operate, whereas a pause occurring at an ungrammatical location and thus not defining a complete or meaningful speech unit may be unusable for the interpreter, or may cause him to act on insufficient information, resulting in inaccurate performance." (10)

Pauses have a second important value for the interpreter as well:"...the more of his own output he can crowd into his source's pauses, the more time he has to listen without interference from his own output." (11) 
The decalage technique developed by Ingram will be useful here as well, for such cues as pauses and obvious clause constructions may be written into the trainer's tapescripts. However, since the difficulty in developing this particular skill is partially due to the speed of delivery of the source text, the technique should be modified to allow the trainee to work with audiotaped texts which vary, not just in complexity and length of sentence construction, but in speed of delivery as well.

Variable-speed recorders are an excellent resource for developing the ability. Exercise tapes such as described earlier may be played on these machines at different speeds, and the student or trainee may begin with a relatively slow-paced tape and gradually build up solid simultaneous skills. The machines are inexpensive, and add great versatility to a lab $\mathrm{Cl}$ training program.

There are several variable-speed recorders on the market. Some will slow down or speed up a cassette tape, but will lower or raise the pitch of the taped voice in doing so, producing an unnatural droning or "chipmunk" effect. These machines can generally only be used with speed reductions or increases of ten per cent or less, and the unnatural vocal effects may prove objectionable to some students.

Other units, such as the VSC Sound Pacer, the VSC Time Cruncher, or Lexicon's very good Varispeech II recorder (no longer manufactured), will allow the trainer to alter the speed of tapes with automatic adjustment of voice pitch, so that the taped voice retains a comparatively natural quality. Some of these units will allow the trainer or student to slow the tape by up to $50 \%$, or to speed it up by as much as $100 \%$, without objectionable distortion of voice frequency level.

The trainer and his students may use these recorders in numerous ways. In the case where an instructor works in the lab with his class, the variable-speed machine may be used as a program input at the console, and exercise tape speed may be closely controlled, while the instructor monitors trainee response from the console. In some labs, the trainee is provided with a variable speed recorder and headphones at his carrel, for self-paced study. Or the variable-speed machine may be used to produce student drill tapes at different speeds from masters recorded at normal speed. The tapes may then be used by the trainee on the lab's student recorders as part of a self-paced program or with supervision from the instructor's console.

When working in a group, simultaneous interpretation trainees in the lab will find it difficult or impossible to work on their lab exercises unless they are seated in the lab with at least one space between them. This should be regarded as a necessity, whether the student is recording or not, as Westman and Chapman recommend; (12); the background noise from other student's practice is a great hindrance to concentration and practice.

If it is desired, the trainee may make a recording of his interpretation--though, of course, not on the variable speed recorder, 
which is not audio-active. He may record his interpretation in one of three ways.

First, he may bring or be supplied with a small personal recorder with a built-in condenser microphone; this may be placed in his carrel, and can be used by the trainee to tape his interpretation. This seemingly makeshift expedient works quite well.

Secondly, he may listen to the lesson tape on an audioactive lab recorder, and record his own voice while he interprets. The disadvantage to this technique is that the student's voice will be mixed with the voice on the lesson tape in his headset and will be a strong distraction (13).

The third alternative is the best, but requires some minor and inexpensive alterations to lab equipment. It consists of the following arrangements:

a) A phone jack should be installed on each student-use recorder or student control panel (in remote labs) which the $\mathrm{Cl}$ trainer wishes to use for simultaneous interpretation training. It should be immediately adjacent to the student's headset microphone jack, and should be of a type that will accept the headset microphone plug. In some circumstances it will be possible to place the input jack in the carrel top.

b) A patch cord may then be run from this jack under the carrel top to a similar phone jack in or near the recorder (or control panel) in an adjacent carrel. This should be a permanent installation, neatly made.

c) When students are to practice simultaneous interpretation, the microphone plug from the headset may be plugged into the phone input jack described in a), above, and a short patch cord may be run from the phone input jack in b) to the adjacent microphone input.

It will now be possible for the student sitting at one recorder to listen to a drill tape and record his interpretation on the next recorder over, without the mixing in his headset of his voice with that on the drill tape. The trainer will have a recording of the student's voice alone, which he may compare with the tapescript or the master tape. In order to restore the lab to its normal capacities (a student in each seat), it is only necessary to remove the short patch cord described in c) and plug the headset microphone plug into the student's recorder's input.

It appears from Barik's research that "proportionally more of the speaker's pauses occur at grammatical juncture points in prepared texts than in spontaneous material." (14) Spontaneous text--a category that includes almost all courtroom speech--seems, from Barik's data, to offer the interpreter only about half as many pauses which may serve in this manner as grammatical cues. The interpreter trainee must learn to wrestle effectively with a lack of such cues, and with pauses which are miscues. It is therefore important that training 
tapes in simultaneous court interpretation introduce the trainee to working with unpaused or poorly paused material--ideally, spontaneous material.

Such materials might best be introduced gradually, after a trainee has gained confidence and abilities at shadowing and Ingram's decalage method and has made some progress toward developing strategies for recoding of source message input. Drill tapes at this point could become more and more realistic, with less scripted material and more in-court recordings used on the tapes.

A caution must be offered with regard to introducing the student of simultaneous interpretation to lab work. The student's first efforts are likely to be trying for him, and he should be carefully prepared for this new educational experience. As Pierre Horn reports, in discussing a college course on conference interpreting:

"During the five weeks allocated to simultaneous interpreting, we did all our work in the laboratory. The students listened to selections of increasing length dealing with, or different from, those used in consecutive work. Because they could no longer take notesexcept perhaps for numbers, dates, and names--the pace seemed hurried, they felt rushed, they skipped words, sentences, mistook tenses, garbled names and places: in short, it was a disaster! But quite soon they learned to readjust their listening and speaking speed, to be only a few words behind the speaker's own, to pay more attention than ever before to what was being said, and in general to be more careful with both their pronunciation and enunciation." (15)

It is recommended that the student's preliminary drilling on simultaneous skills include a solid introduction to shadowing without interpreting, in order to build cumulative skills and minimize "lab anxiety."

Ability to remember the content of statements during consecutive interpretation; Ability to manage very long statements during consecutive interpretation.

These two skills needs, singled out by survey respondents, can be resolved to some degree, perhaps, by a trainee's development or adoption of a simple note-taking technique. Such techniques can be a help when what is at point is remembering names, numbers, dates, times, and a variety of other types of data. What is included in such notes will depend on the proficiency and abilities of the trainee and will therefore vary widely.

However, many memory problems, and other problems, with consecutive interpretation of long sentences cannot be efficiently solved by note taking. The court interpreter is required to interpret all dialogue as faithfully as possible, and this dialogue will often include statements which are poorly constructed. Court personnel will 
frequently imbed incomplete fragments in sentences, or simply stop in the middle of a sentence and begin again. Quite frequently, lawyers and jurists will speak in the passive voice, or will include two negatives in a statement or a question--for instance, "Did you not claim that the car had not been stolen?" Such questions and statements often have no exact analogue in Spanish, and must be interpreted with care. And, of course, the complexity and length of much courtroom speech is itself a barrier to recall. With such difficulties, the interpreter will need highly-developed immediate recall skills, and strategies, developed from practice, for accurate, unambiguous consecutive interpretation.

Once again, the student must learn to organize and remember the information that appears in the sentence he is interpreting. Using the lab to develop the trainee's ability to remember statement content, and to manage very long statements during consecutive interpretation, will require that the $\mathrm{Cl}$ trainer script and produce drill tapes. Each sentence drill should be followed by a pause long enough to allow the student to record his interpretation. In preparing EnglishSpanish drill tapes, it is helpful to remember that Spanish translations of English texts are, on the average, about one third longer than the original English text. (16)

The sentences should be taped in graduated degrees of difficulty. Those will be easiest which are relatively short and have clear clause and phrase structures, inviting the trainee to remember word groups. Much harder will be poorly constructed sentences which do not readily fall into such easily perceived units of meaning, e.g., sentences with double negatives, sentences in passive voice, sentences with addresses and other numeric data, and sentences in which the word order in the source language departs widely from the word order in the target language. (A simple example: the noun usually follows its adjectives in English, but usually precedes them in Spanish.) These and other types of difficulty (17) can be gradually introduced on the tapes, until the student has learned to listen for groups of words, rather than individual words, even in the most trying circumstances.

\section{Knowledge of English legal terms.}

The interpretation of legal terms from English to Spanish poses special difficulties for the trainee. Virtually all of us are unfamiliar with much English legal jargon. Though several Spanish-English legal dictionaries are quite useful, no glossary or dictionary will suffice to resolve all of the interpreter trainee's difficulties with English legal jargon, for not all English legal terms have lexical analogues in Spanish. When such a term is imbedded in a statement, interpretation skills, and not mere knowledge of English legal vocabulary and its Spanish counterparts, are required. The lab can be helpful in building these skills. 
Consider, for example, the following sentence:

I want to make sure that the defendant understands that his priorable offense will be carefully considered by this court in sentencing if he pleads guilty to this charge.

The phrase "priorable offense" here refers to past convictions on the defendant's record which the court may legally consider in imposing sentence for an offense of which the defendant is accused. This phrase has no lexical analogue in Spanish, and while the phrase itself may be given a Spanish definition, an interpretation of the above which simply substituted the Spanish definition for the English phrase would likely be confusing, if not incoherent; it would certainly be time-consuming and cumbersome. The trainer's best use of the lab in such cases as this would be to introduce such terms, and model interpretations of sentences in which they are used, in lectures. Sentence interpretation drills containing these terms can then be scripted by the trainer and recorded by the lab staff for use in the language laboratory. The student may then practice these drills in the lab--first consecutively, and then, when some mastery of the difficult phrases and terms has been gained through consecutive interpretation, simultaneously.

\section{General Objectives of $\mathrm{CI}$ Programs in the Language Laboratory}

In any preparation of lab materials and procedures for $\mathrm{Cl}$ training, the staff of the lab, and the trainers, will wish to concentrate on the specific skills and behaviors that their clientele requires. The object of $\mathrm{Cl}$ training is to develop in the trainee the level of those several skills earlier listed required for professional performance in a court of law, deposition hearing, inquest, or similar proceeding. Thoughtful composition of lab tape materials will accordingly require that the skill levels desired be established in advance by the $\mathrm{Cl}$ trainer and that taped exercises be composed and produced which:

a. target particular skills and do not mix skills any more than is unavoidable until the student is well prepared;

b. are graduated to allow skills development;

c. are improved and expanded or deleted as trial and error, and experience, would indicate;

d. allow faculty to evaluate student skills objectively. Such evaluations should include a program of pre-testing and post-testing on individual skills, and global testing for overall performance, in accordance with skill levels earlier established by the trainer.

Such a $\mathrm{Cl}$ training program is performance-based, vital, growing, and assures its clientele and its parent institution of solid professionalism in its graduates or certificate holders. A conscientious lab support effort for such a program will prove to be a creditable professional achievement in any language laboratory. 
(1) U.S., Department of Commerce, Bureau of the Census: 1980 Census of Population. Supplementary Report: Persons of Spanish Origin by State: 1980, p. 6. There is reason to believe that this figure is low, and that large numbers of undocumented immigrants were not included in the census date.

(2) U.S., Department of Commerce, Bureau of the Census: 1980 Census of Population, Supplementary Report: Provisional Estimates of Social, Economic, and Housing Characteristics, 1980, p. 14 (sum of figures for individuals of age 5 or greater).

(3) The sixth amendment guarantees the right of the accused to confront his accuser(s). Such confrontation cannot take place if testimony is incomprehensible to the accused; cf. the precedent-setting case United States ex rel. Negron v. New York, 434 F.2d 386 (1970), and United States vs. Carrion, 488 F.2d 12 (1st Circuit, 1973). Also see Joan Bainbridge Safford, "No Comprendo: The Non-English-Speaking Defendant and the Criminal Process," The Journal of Criminal Law and Criminology, 68, 1 (1977), pp. 15-30.

(4) Stafford (p. 15) stated in 1977 that at that time "thirty-five states (had) some statutory provision for appointment of interpreters in specified cases." California's statutory provisions are representative of the trend in some southern and southwestern states toward requiring of interpreters that they demonstrate professional skills in state-administered examination. Cf. Calif. Stats. 1978, ch. 158; Assem. Bill No. 2400--Arnett. The greatest need for court interpreters is for those whose expertise is in Spanish-English interpreting. In a 1980 study conducted by the Judicial Council of California, for instance, it was disclosed that in $98 \%$ of cases in which court interpreters were used in California's courts in one eight-week period, Spanish-English interpretive skills were required--a total of 28,602 cases in eight weeks alone, as opposed to only 161 cases in which Vietnamese-English interpreters (the second strongest need) were required. See Judicial Council of California, "Court Interpreter Study," in the JCC's Annual Report to the Covernor and the Legislature, January 1, 1981, Part 1, Chapter 2, n.p.

(5) For additional information on this survey, see Head, Gerald L. and Stromberg, Wayne H.: "Training Needs for California's Spanish-English Court Interpreters," Channels, 2 (December 1983), No. 5, pp. 6-8.

(6) The $\mathrm{Cl}$ trainer and lab staff may well choose to remember, in this connection, that most interpreters do not work in federal courts, and that some evidence from southwestern states indicates that more than $80 \%$ of cases requiring interpreters are heard in municipal courts. Cf. JCC, "Court Interpreting Study," op. cit., n.p.

(7) Robert Ingram, "Teaching Decalage Skills," unpublished paper presented at Fourth National Conference of Interpreter Trainers, Pacific Grove, California, February 21, 1983, p. 11; forthcoming in proceedings of the conference.

(8) G.A. Miller, "The Magical Number Seven, Plus or Minus Two: Some Limits on Our Capacity for Proceeding Information," The Psychological Review, 63 (1956), 2, 93.

(9) Ingram, op. cit., p. 11

(10) Henri Barik, "A Description of Various Types of Omissions, Additions, and Errors of Translation Encountered in Simultaneous Interpretation." Meta, 16 (1971), 4, 199. Barik enumerates subclasses of interpretation departure.

(11) Barik, op. cit., pp. 200-204.

(12) Donald Westman and Craig Chapman, "Applications of the Language Laboratory to Training in Simultaneous Interpretation," Meta, 22 (1977), 4, 264.

(13) Westman and Chapman, op. cit., p. 267. 
(14) Henri Barik, "Simultaneous Interpretation: Qualitative and Linguistic Data," Language and Speech, 18 (1975), 3, 274.

(15) Pierre L. Horn, "The Methodology of a College Course in Interpreting," Modern Language Journal, 59 (1975), 1-2, 26.

(16) Alexandre Rainof, "How Best to Use an Interpreter in Court," California State Bar Journal, 55 (May 1980), 198.

(17) Rainof, op. cit., pp. 196-200, enumerates several special syntactic problems for the Spanish-English court interpreter, including some of those mentioned.

\section{Appendix}

Spanish-English court interpreters were asked to grade twentytwo aspects of, or skills involved in, court interpretation in terms of their difficulty and in terms of their importance to the beginning court interpreter, according to the scale reproduced in Table 1 below. Survey results are reported in Tables 2 and 3 below. In each case, skills are ordered from least difficult or important to most difficult or important.

\section{TABLE I}

\section{SCALE FOR RATING INTERPRETER SKILLS ACCORDING TO DIFFICULTY AND IMPORTANCE TO THE BEGINNING INTERPRETER}

\begin{tabular}{|c|c|c|c|}
\hline Rating & \multicolumn{2}{|c|}{$\begin{array}{l}\text { Definition of Values: } \\
\text { Scale of Difficulty } \\
\text { for the Beginning } \\
\text { Interpreter }\end{array}$} & $\begin{array}{l}\text { Definition of Values: } \\
\text { Scale of Importance } \\
\text { for the Beginning } \\
\text { Interpreter }\end{array}$ \\
\hline 1 & \multicolumn{2}{|c|}{ Never difficult } & Never important \\
\hline 2 & \multicolumn{2}{|c|}{ Seldom difficult } & Seldom important \\
\hline 3 & \multicolumn{2}{|c|}{ Sometimes difficult } & Sometimes important \\
\hline 4 & \multicolumn{2}{|c|}{ Always difficult } & Always important \\
\hline & \multicolumn{3}{|c|}{ TABLE 2} \\
\hline & \multicolumn{3}{|c|}{$\begin{array}{l}\text { SCALE OF DIFFICULTY } \\
\text { FOR THE BEGINNING INTERPRETER }\end{array}$} \\
\hline No. & Mean Score & \multicolumn{2}{|c|}{$\begin{array}{l}\text { Aspect of Interpretation, or Interpretation } \\
\text { Skill }\end{array}$} \\
\hline 1. & 2.097 & \multicolumn{2}{|c|}{$\begin{array}{l}\text { Maintaining a professional relationship } \\
\text { with court personnel }\end{array}$} \\
\hline 2. & 2.139 & $\begin{array}{l}\text { Familiarity } \\
\text { ethics }\end{array}$ & th interpreters' code of \\
\hline $\begin{array}{l}3 . \\
4 .\end{array}$ & $\begin{array}{l}2.536 \\
2.818\end{array}$ & \multicolumn{2}{|c|}{$\begin{array}{l}\text { Taking accurate notes } \\
\text { Skill in sight translations }\end{array}$} \\
\hline
\end{tabular}




$\begin{array}{rr}5 . & 2.819 \\ 6 . & 2.840 \\ 7 . & 2.843 \\ & \\ 8 . & 2.870 \\ 9 . & 2.891 \\ 10 . & 2.904 \\ 11 . & 3.000\end{array}$

12.

13.

14.

3.077

15.

3.078

16.

17.

18.

19.

20.

3.282

21.

22.
Familiarity with courtroom proceedings Ability to interpret quickly during summary interpretation

Resisting opportunities or requests to explain, clarify, or correct something that has been said

Maintaining concentration during interpreting.

Ability to make accurate word or phrase choices in summary interpretation

Knowledge of Spanish idioms (example: "...me tomo el pelo...")

Remembering the content of a document to be interpreted while doing summary interpretation

Ability to interpret quickly during consecutive interpretation

Knowledge of Spanish drug terms

Ability to make accurate word or phrase choices in consecutive interpretation

Knowledge of Spanish slang terms

Ability to meaningfully interpret a witness's nongrammatical sentences and/or regionalisms

Ability to make accurate word or phrase choices in simultaneous interpretation

Knowledge of Spanish specialty vocabularies (for example: maritime or medical terms)

Ability to "keep up" accurately with the witness during simultaneous interpreting Knowledge of English legal terms

Remembering the content of statements while engaged in consecutive interpretation

Ability to manage very long sentences when doing consecutive interpretation 


\section{TABLE 3}

\section{SCALE OF IMPORTANCE FOR THE BEGINNING INTERPRETER}

\begin{tabular}{|c|c|c|}
\hline $\begin{array}{l}\text { No. } \\
1 .\end{array}$ & $\begin{array}{l}\text { Mean Score } \\
3.217\end{array}$ & $\begin{array}{l}\text { Aspect of Interpretation } \\
\text { Knowledge of Spanish specialty vocabu- } \\
\text { laries (for example: maritime or medical } \\
\text { terms) }\end{array}$ \\
\hline $\begin{array}{l}2 . \\
3 .\end{array}$ & $\begin{array}{l}3.274 \\
3.358\end{array}$ & $\begin{array}{l}\text { Knowledge of Spanish drug terms } \\
\text { Ability to interpret quickly during sum- } \\
\text { mary interpretation }\end{array}$ \\
\hline $\begin{array}{l}4 . \\
5 . \\
6 .\end{array}$ & $\begin{array}{l}3.378 \\
3.378 \\
3.455\end{array}$ & $\begin{array}{l}\text { Taking accurate notes } \\
\text { Skill in sight translations } \\
\text { Ability to make accurate word or phrase } \\
\text { choices in summary interpretation }\end{array}$ \\
\hline $\begin{array}{l}7 . \\
8 .\end{array}$ & $\begin{array}{l}3.491 \\
3.532\end{array}$ & $\begin{array}{l}\text { Knowledge of Spanish slang terms } \\
\text { Remembering the content of a document } \\
\text { to be interpreted while doing summary } \\
\text { interpretation }\end{array}$ \\
\hline 9. & 3.548 & $\begin{array}{l}\text { Knowledge of Spanish idioms (example: } \\
\text { "...me tomo el pelo...") }\end{array}$ \\
\hline 10. & 3.550 & $\begin{array}{l}\text { Resisting opportunities or requests to } \\
\text { explain, clarify, or correct something that } \\
\text { has been said }\end{array}$ \\
\hline 11. & 3.623 & $\begin{array}{l}\text { Ability to interpret a witness's nongram- } \\
\text { matical sentences and/or regionalisms }\end{array}$ \\
\hline 12. & 3.623 & $\begin{array}{l}\text { Ability to interpret quickly during conse- } \\
\text { cutive interpretation }\end{array}$ \\
\hline 13. & 3.709 & $\begin{array}{l}\text { Ability to manage very long sentences } \\
\text { when doing consecutive interpretation }\end{array}$ \\
\hline 14. & 3.722 & $\begin{array}{l}\text { Maintaining a professional relationship } \\
\text { with court personnel }\end{array}$ \\
\hline $\begin{array}{l}15 . \\
16 .\end{array}$ & $\begin{array}{l}3.735 \\
3.783\end{array}$ & $\begin{array}{l}\text { Familiarity with courtroom proceedings } \\
\text { Familiarity with interpreters' code of } \\
\text { ethics }\end{array}$ \\
\hline 17. & 3.810 & $\begin{array}{l}\text { Ability to make accurate word or phrase } \\
\text { choices in consecutive interpretation }\end{array}$ \\
\hline 18. & 3.819 & $\begin{array}{l}\text { Ability to make accurate word or phrase } \\
\text { choices in simultaneous interpretation }\end{array}$ \\
\hline $\begin{array}{l}19 . \\
20 .\end{array}$ & $\begin{array}{l}3.836 \\
3.861\end{array}$ & $\begin{array}{l}\text { Knowledge of English legal terms } \\
\text { Remembering the content of statements } \\
\text { while engaged in consecutive interpreta- } \\
\text { tion }\end{array}$ \\
\hline 21 & 3.905 & $\begin{array}{l}\text { Ability to "keep up" accurately with the } \\
\text { witness during simultaneous interpreting }\end{array}$ \\
\hline 22 & 3.940 & $\begin{array}{l}\text { Maintaining concentration during } \\
\text { preting. }\end{array}$ \\
\hline
\end{tabular}

